\title{
Oxytocin Modulates Glutamatergic Synaptic Transmission between Cultured Neonatal Spinal Cord Dorsal Horn Neurons
}

\author{
Young-Hwan Jo, Marie-Elisabeth Stoeckel, Marie-José Freund-Mercier, and Rémy Schlichter \\ Laboratoire de Neurophysiologie Cellulaire et Intégrée, Unité Mixte de Recherche 7519-Centre National de la Recherche \\ Scientifique, Université Louis Pasteur, 67084 Strasbourg Cedex, France
}

\begin{abstract}
The functional characteristics of binding sites for the neuropeptide oxytocin (OT) detected by radioautography in laminae I and II of the dorsal horn (DH) and on cultured neonatal $\mathrm{DH}$ neurons were studied on the latter using perforated patch-clamp recordings. The neurons were identified by their spike discharge properties and on the basis of the presence of met-enkephalinlike and glutamate decarboxylase-like immunoreactivities. OT (100 nM) never induced any membrane current at a holding potential of $-60 \mathrm{mV}$ but increased the frequency of spontaneously occurring AMPA receptor-mediated EPSCs or the mean amplitude of electrically evoked EPSCs in a subset (35\%) of neurons. The frequency of miniature EPSCs (m-EPSCs) recorded in the presence of $0.5 \mu \mathrm{M}$ tetrodotoxin was also increased by OT (100 nM) without any change in their mean
\end{abstract}

amplitude, indicating an action at a site close to the presynaptic terminal. The decay kinetics of any type of EPSC were never modified by OT. The effect of OT was reproduced by $\left[\mathrm{Thr}^{4}\right.$, Gly ${ }^{7}$ ]-OT (100 nM), a selective OT receptor agonist, and blocked by $\mathrm{d}\left(\mathrm{CH}_{2}\right)_{5}-\left[\mathrm{Tyr}(\mathrm{Me})^{2}, \mathrm{Thr}^{4}\right.$, Tyr- $\left.\mathrm{NH}_{2}{ }^{9}\right]$-ornithine vasotocin (100 nM), a specific OT receptor antagonist. Reducing the extracellular $\mathrm{Ca}^{2+}$ concentration from 2.5 to $0.3 \mathrm{~mm}$ in the presence of $\mathrm{Cd}^{2+}(100 \mu \mathrm{M})$ reversibly blocked the effect of OT on m-EPSCs. The OT receptors described here may represent the substrate for modulatory actions of descending hypothalamo-spinal OT-containing pathways on the nociceptive system.

Key words: EPSCs; oxytocin; AMPA receptors; nociception; Met-enkephalin; GABA; dorsal horn neurons; spinal cord
The dorsal horn of the spinal cord gray matter is involved in the transmission of peripheral nociceptive signals and in their modulation. In particular, the interneurons located in laminae I and II and the spino-thalamic projection neurons of laminae I, II, and V are the targets for several descending, inhibitory, painmodulating pathways originating from brainstem structures such as the nucleus raphe magnus, the locus coeruleus, or the medullary reticular formation (Besson and Chaouch, 1987; Willis et al., 1995).

In general, activation of the nociceptive system is accompanied by autonomic reactions such as increases in respiratory and cardiac frequencies, arterial pressure, or sweating, which are likely to involve or to be modulated by the hypothalamus. The existence of spino-hypothalamic pathways that can be activated by nociceptive stimuli has been reported (Burnstein et al., 1987; Dado et al., 1994a,b). The cell bodies of the projection neurons are located in the most superficial laminae of the dorsal horn as well as in the lateral spinal nucleus and in lamina $X$, and their axons terminate in the lateral and/or medial divisions of the hypothalamus. Functional descending hypothalamo-spinal projections have also been described, because electrical (Carstens et al., 1982) or chemical (Workman and Lumb, 1997) stimulation of the anterior hypothalamus induces an inhibition of nociceptive neurons located in

\footnotetext{
Received Aug. 20, 1997; revised Jan. 7, 1998; accepted Jan. 16, 1998.

This research was supported by a grant from the UPSA Pain Institute and by Université Louis Pasteur and Centre National de la Recherche Scientifique. We thank C. Moreau, M. J. Klein, B. Waltisperger, and M. Roth for excellent technical assistance and J. M. Gachon for photographic work. We also thank Dr. D. Lodge (Eli-Lilly) for the gift of GYKI53655, Dr. M. Manning for the gift of oxytocin agonists and antagonists, and Dr. M. Tappaz for the gift of GAD antibody.

Correspondence should be addressed to R. Schlichter, Université Louis Pasteur, Unité Mixte de Recherche 7519-Centre National de la Recherche Scientifique, 21 rue Descartes, 67084 Strasbourg Cedex, France.

Copyright (C) 1998 Society for Neuroscience $\quad 0270-6474 / 98 / 182377-10 \$ 05.00 / 0$
}

the deep dorsal horn (laminae IV-VI). The best anatomically documented direct hypothalamo-spinal projection originates from the parvocellular neurons of the paraventricular nucleus and contains several neuropeptides, among which oxytocin (OT) is the most abundant compared with vasopressin or Met-enkephalin (Saper et al., 1976). These fibers terminate in laminae I and II as well as in two autonomic areas: the intermediolateral cell column and lamina X (Sofroniew, 1985; Cechetto and Saper, 1988). Oxytocin-containing terminals form axodendritic synapses with lamina II neurons (Rousselot et al., 1990), and there is a good match between the projection sites of oxytocinergic hypothalamospinal neurons and the distribution of OT binding sites in the spinal cord (Reiter et al., 1994). However, little is known concerning the functionality and the physiological role of these OT binding sites. Some studies suggest an absence of effect of OT on the nociceptive system (Millan et al., 1984; Xu and WiesenfeldHallin, 1994), whereas others have reported antinociceptive effects of OT (Arletti et al., 1993; Lundeberg et al., 1994).

The most superficial laminae (I-III) contain both inhibitory (GABAergic and glycinergic) and excitatory (glutamatergic) interneurons coexpressing a variety of neuropeptides (Todd and Spike, 1993). Among these interneurons, which could both be the target for the descending OT-containing pathway, much less is known concerning glutamatergic neurons compared with GABAergic and/or glycinergic neurons (Todd and Spike, 1993). To study the effects of OT at the cellular level and in particular on the glutamatergic excitatory synaptic transmission between dorsal horn (DH) neurons, we have developed a culture of superficial DH neurons from neonatal rats. The DH neurons were identified electrophysiologically with the perforated patch-clamp technique and by immunolabeling with antibodies against glutamic acid decarboxylase and Met-enkephalin. 


\section{MATERIALS AND METHODS}

Tissue culture. Primary cultures of spinal dorsal horn neurons were prepared from 3- to 4-d-old Wistar rats. After decapitation of the animals under deep diethylether anesthesia, a laminectomy was performed, and the dorsal third of the spinal cord was cut with a razor blade. These tissue fragments were incubated for $45 \mathrm{~min}$ at $37^{\circ} \mathrm{C}$ in oxygenated, divalent-free Earle's balanced salt solution (EBSS, Life Technologies) containing papain $(20 \mathrm{U} / \mathrm{ml}$, Sigma). The enzymatic digestion was stopped by adding $3 \mathrm{ml}$ of EBSS containing bovine serum albumin (1 $\mathrm{mg} / \mathrm{ml}$, Sigma $)$, trypsin inhibitor $(10 \mathrm{mg} / \mathrm{ml}$, Sigma $)$, and DNase $(0.01 \%$, Sigma $)$, and a mechanical dissociation was performed with a $1 \mathrm{ml}$ plastic pipette. The homogenate was deposited on top of $4 \mathrm{ml}$ of a solution of composition similar to that described above, except that the concentration of bovine serum albumin was increased to $10 \mathrm{mg} / \mathrm{ml}$. After centrifugation (5 min at 500 $\mathrm{rpm}$ ), the supernatant was removed and replaced with $5 \mathrm{ml}$ of culture medium, the composition of which was the following: MEM- $\alpha$ (Life Technologies), fetal calf serum $(5 \% \mathrm{v} / \mathrm{v}$, Life Technologies), heatinactivated horse serum $(5 \% \mathrm{v} / \mathrm{v}$, Life Technologies $)$, penicillin and streptomycin (50 IU/ml each, Life Technologies), transferrin (10 mg/ml, Sigma), insulin (5 mg/ml, Sigma), putrescine (100 nM, Sigma), and progesterone (20 nM, Sigma). Transferrin, insulin, putrescine, and progesterone were added to promote cell survival (Bottenstein and Sato, 1979). After mechanical dissociation with a fire-polished pasteur pipette, cells were plated onto $35 \mathrm{~mm}$ collagen-coated plastic culture dishes, which were modified by heating in a press (BB-form2, Mecanex) to print an alphabetical grid on the bottom of the dish. Each square of the grid $(300 \times 300 \mu \mathrm{m})$ was identified by two letters (Bader et al., 1987) and allowed to localize the recorded neuron during immunolabeling. The heat modification procedure of the culture dishes reduced the thickness of the plastic to $\sim 0.1 \mathrm{~mm}$, which considerably reduced the autofluorescence of the plastic and allowed us to perform immunofluorescence experiments. Cultures were maintained in a water-saturated atmosphere $\left(95 \%\right.$ air and $5 \% \mathrm{CO}_{2}$ ) at $37^{\circ} \mathrm{C}$ until use. Two days after seeding the cells, cytosine arabinoside $(10 \mu \mathrm{M})$ was added to the culture medium for $24 \mathrm{hr}$ to reduce glial proliferation.

Electrophysiological recordings. Experiments were performed at room temperature $\left(20-22^{\circ} \mathrm{C}\right)$ after $6-21 \mathrm{~d}$ in culture. Patch-clamp recordings were made with the perforated patch-clamp technique using amphotericin B as the pore-forming agent (Rae et al., 1991) with an Axopatch 200A amplifier (Axon instruments) and low-resistance (3-4 M $\Omega$ ) electrodes. The external solution contained (in mM): $\mathrm{NaCl} 135, \mathrm{KCl} 5, \mathrm{CaCl}_{2}$ 2.5, $\mathrm{MgCl}_{2}$ 1, HEPES 5, and glucose 10, pH 7.3. The experiments described in this study concern the modulation of glutamatergic synaptic transmission by oxytocin. Therefore, the external solution also contained bicuculline $(10 \mu \mathrm{M})$ and strychnine $(1 \mu \mathrm{M})$ to block fast GABAergic and glycinergic inhibitory transmissions. The pipette was first filled at its tip with a solution containing (in mM): $\mathrm{KCl} 125, \mathrm{CaCl}_{2} 5, \mathrm{MgCl}_{2} 2$, HEPES 10, and EGTA 10, pH 7.3, and then backfilled with the same solution containing amphotericin B $(150 \mu \mathrm{g} / \mathrm{ml})$. The amphotericin B (Sigma) stock solution $(30 \mathrm{mg} / \mathrm{ml})$ was prepared in dimethyl sulfoxide (DMSO) just before the recording session. Voltage and current traces were stored digitally on a videotape recorder (sampling rate, $20 \mathrm{kHz}$ ) and/or on a personal computer after being filtered at $5 \mathrm{KHz}$ by the Axopatch 200A. Acquisition and analysis were performed with the pClamp6 and Axograph 3 software (Axon Instruments). Details on the analysis of synaptic currents can be found elsewhere (Poisbeau et al., 1996).

In some experiments, the external calcium concentration was reduced to $0.3 \mathrm{~mm}$. In this case, the magnesium concentration was raised to $10 \mathrm{~mm}$.

Drugs and application of substances. All substances were prepared as $1000 \times$ concentrated stock solutions. Bicuculline (Sigma), strychnine (Sig$\mathrm{ma}$ ), and tetrodotoxin (TTX, Latoxan) were prepared in distilled water and stored at $-20^{\circ} \mathrm{C}$. 6-Cyano-7-nitroquinoxaline-2,3-dione (CNQX, Tocris Cookson) and GYKI53655 (a kind gift from Dr. D. Lodge, Eli-Lilly) were prepared in DMSO and stored at $4^{\circ} \mathrm{C}$. Oxytocin (Bachem), the selective oxytocin antagonist $\mathrm{d}\left(\mathrm{CH}_{2}\right)_{5}-\left[\mathrm{Tyr}(\mathrm{Me})^{2}, \mathrm{Thr}^{4}, \mathrm{Tyr}^{-\mathrm{NH}_{2}}{ }^{9}\right]$-ornithine vasotocin, and the oxytocin agonist $\left[\mathrm{Thr}^{4}\right.$, Gly $\left.{ }^{7}\right]$-OT (both kind gifts from Dr. M. Manning, Medical College of Ohio, Toledo, $\mathrm{OH}$ ) were prepared in acetic acid $(0.25 \%)$ and stored at $4^{\circ} \mathrm{C}$. The substances to be tested were dissolved at final concentration in extracellular solution just before the recording session and were applied by bath perfusion.

Electrical stimulation. Extracellular electrical stimulation was applied to the cell body of the presynaptic neuron with two patch pipettes filled with extracellular solution (resistance, $\leq 1 \mathrm{M} \Omega$ ) and glued tip to tip under a stereomicroscope using dental wax. The tips of the two pipettes were usually separated by $<50 \mu \mathrm{m}$. The electrodes were connected to the output of a pulse generator (one electrode to the positive output, the other to the negative output). The duration of the stimuli was $0.1 \mathrm{msec}$ in all experiments, and the stimulation intensity used varied between -10 and $-20 \mathrm{~V}$.

Immunolabeling. After the recording session, the cultures were fixed for $30 \mathrm{~min}$ at room temperature in $4 \%$ paraformaldehyde in $0.1 \mathrm{M}$ phosphate buffer, $\mathrm{pH} 7.4$, and subsequently rinsed three times in PBS. To perform the double immunolabeling of glutamic acid decarboxylase (GAD) and Met-enkephalin (Met-ENK), cultures were permeabilized with $0.5 \%$ Triton X-100 in PBS and incubated overnight at room temperature with a goat polyclonal antibody against GAD (1:750; a gift from Dr. M. Tappaz, U 433, Lyon, France) and a rabbit polyclonal antibody against Met-ENK (1:2000, Tebu). Cultures were rinsed three times with PBS and incubated for $1 \mathrm{hr}$ at room temperature with a fluorescein isothiocyanate-conjugated anti-goat IgG (1:200, Biosys) to reveal GADlike immunoreactivity and a Cy3-conjugated anti-rabbit $\operatorname{IgG}(1: 400$; Jackson ImmunoResearch, West Grove, PA) to reveal Met-ENK-like immunoreactivity.

Radioautography. The radioautographic detection of OT binding sites was performed by using the radioiodinated selective oxytocin antagonist $\mathrm{d}\left(\mathrm{CH}_{2}\right)_{5}-\left[\mathrm{Tyr}(\mathrm{Me})^{2}, \mathrm{Thr}^{4}, \mathrm{Tyr}-\mathrm{NH}_{2}{ }^{9}\right]$-ornithine vasotocin. The peptide was iodinated using chloramine $\mathrm{T}$, and the monoiodinated ligand was purified on a reverse phase column by HPLC as described by Stoeckel and Freund-Mercier (1989).

Radioligand binding was performed on cultures of dorsal horn neurons grown on collagen-coated glass coverslips and on spinal cord transverse sections $(20 \mu \mathrm{m})$ cut on a cryostat microtome and thaw-mounted on gelatin-coated slides. The two types of preparations were preincubated for $20 \mathrm{~min}$ in Tris buffer (Tris- $\mathrm{HCl} 85 \mathrm{~mm}, \mathrm{MgCl}_{2} 5 \mathrm{~mm}$, and BSA $0.1 \%$, $\mathrm{pH} \mathrm{7.4)}$ at $37^{\circ} \mathrm{C}$ for the cultures and at room temperature for the sections. The incubations were performed in the same buffer containing $30 \mathrm{pm}$ ${ }^{125} \mathrm{I}$-OT antagonist, $90 \mathrm{~min}$ at $37^{\circ} \mathrm{C}$ for the cultures and $24 \mathrm{hr}$ at $4^{\circ} \mathrm{C}$ for the sections. The incubations were followed by three $5 \mathrm{~min}$ washes in cold buffer $\left(4^{\circ} \mathrm{C}\right)$. The cultures were immediately treated for $1 \mathrm{hr}$ with $4 \%$ paraformaldehyde, washed with distilled water, and air-dried. The sections were rapidly rinsed in cold distilled water, dried with a cold air stream, and treated with paraformaldehyde vapors at $80^{\circ} \mathrm{C}$ for $3 \mathrm{hr}$.

Historadioautographic technique was applied by coating the preparations with LM-1 emulsion (Amersham) and stored in light-tight boxes at $4^{\circ} \mathrm{C}$. After 20-30 d exposure, they were developed for $5 \mathrm{~min}$ in D19 (Kodak) at $18^{\circ} \mathrm{C}$ and slightly stained with thionine. They were mounted with Eukit (Kindler, Freiburg, Germany) and observed in dark-field and bright-field light microscopy.

All quantitative results given in this paper are expressed as mean \pm SEM.

\section{RESULTS}

\section{Localization of OT binding sites}

Figure 1 shows the distribution of OT binding sites on transverse spinal cord sections and on cultured DH neurons. The densest labeling was observed in the most superficial laminae (I and II), where most nociceptive primary afferents terminate (Fig. $1 A$ ). Slightly less intense labeling was detected in the region of the intermediolateral cell column and in the dorsal part of lamina X surrounding the central canal, both structures containing preganglonic sympathetic neurons.

A subset of cultured DH neurons also showed a high density of OT binding sites (Fig. 1B). The labeled regions included the cell body and the neurites. Occasionally it was possible to observe only a labeling of the neurites. In contrast, a labeling of the cell body without a labeling of the neurites was never detected. Taken together, these results indicate that at least a fraction of the OT binding sites detected in situ are localized on superficial dorsal horn neurons.

\section{Electrophysiological and immunocytochemical identification of different types of DH neurons}

The electrophysiological characteristics of DH neurons were determined with the perforated patch-clamp method. In the current-clamp mode, four types of neurons were identified by 

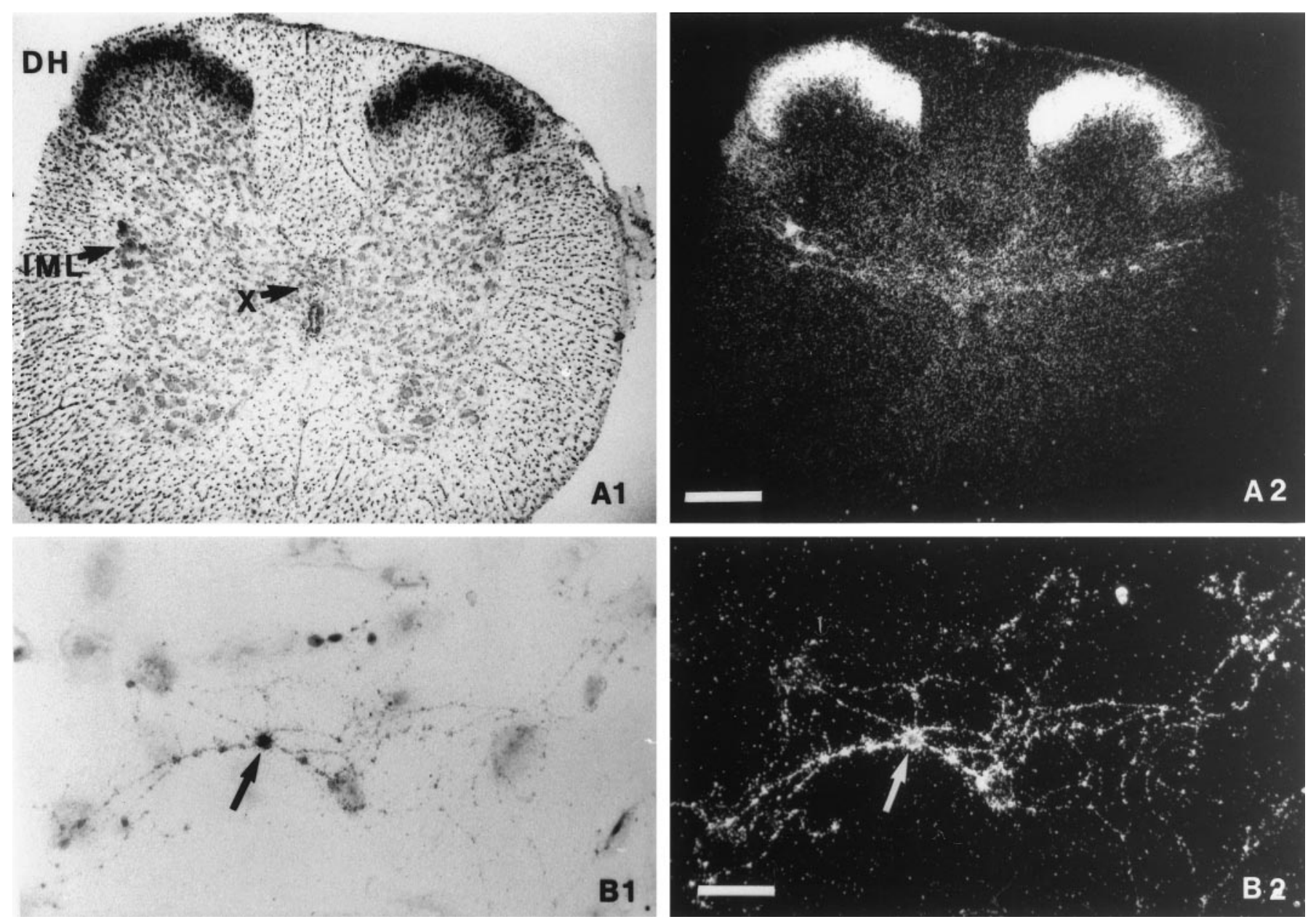

Figure 1. Historadioautographic detection of OT binding sites. $A 1, B 1$, Bright-field photomicrographs; $A 2, B 2$, dark-field photomicrographs. $A$, Transverse spinal cord section of a 15-d-old rat at the upper lumbar level showing a high density of OT binding sites in the DH, the intermediolateral cell column $(I M L)$, and lamina X $(X)$ dorsally to the central canal. Scale bar, $250 \mu \mathrm{m}$. B. Culture of dissociated DH neurons after $12 \mathrm{~d}$ in vitro. OT binding sites were present on a cell body (arrow) and its related neurites. Scale bar, $25 \mu \mathrm{m}$.

their spike discharge pattern in response to $900 \mathrm{msec}$ lasting intracellular current pulses (Fig. 2).

Type 1 neurons (Fig. $2 A$ ) were characterized by a continuous train of action potentials during suprathreshold depolarizing current pulses, with no obvious sign of spike accommodation or attenuation. In contrast, type 2 neurons (Fig. $2 B$ ) showed marked spike accommodation and spike attenuation properties and discharged a burst of action potentials never exceeding a total duration of $500 \mathrm{msec}$. Type 3 neurons (Fig. 2C) fired a single action potential on depolarization regardless of the intensity of the current pulse applied. Finally, type 4 neurons (Fig. 2D) exhibited tonic firing during moderate depolarization and marked spike accommodation for larger depolarizing current pulses. Only type 4 neurons possessed an inwardly rectifying current, which was activated during membrane hyperpolarization and resulted in an initial sag on the membrane potential trace. Type 1-4 neurons represented, respectively, 15.5, 36.7, 32.2, and $15.5 \%$ of the total population $(n=100)$.

Taking advantage of a labeled grid printed onto the bottom of the culture dishes, we were able to correlate the electrophysiological properties of the neurons with their neuropeptide content. In a sample of 59 electrophysiologically identified neurons, 25 cells $(42.4 \%)$ colocalized glutamic acid decarboxylase-like
(GAD-LI) and Met-enkephalin-like (Met-ENK-LI) immunoreactivities as determined using a double-immunolabeling technique (see Materials and Methods). Among these 25 neurons that colocalized GAD-LI and Met-ENK-LI, type 1-4 neurons represented $4,64,20$, and $12 \%$ of the total population.

\section{Properties of excitatory synaptic transmission between DH neurons}

After $5 \mathrm{~d}$ in culture it was possible to record spontaneous inhibitory and excitatory synaptic currents. The inhibitory currents were mediated by $\mathrm{GABA}_{\mathrm{A}}$ receptors and/or glycine receptors because they were blocked by bicuculline $(10 \mu \mathrm{M})$ and strychnine $(1 \mu \mathrm{M})$, respectively. OT seemed to modulate preferentially glutamatergic synaptic transmission (see below). Therefore, and to isolate the EPSCs, all extracellular solutions contained bicuculline and strychnine at the concentrations mentioned above. Under these conditions, we recorded spontaneous EPSCs (s-EPSCs; Fig. $3 A)$, which were reversibly blocked by CNQX $(10 \mu \mathrm{M})$ in all cells tested $(n=9)$, suggesting that these EPSCs were mediated by activation of AMPA-type glutamate receptors. CNQX (10-50 $\mu \mathrm{M})$ also reversibly blocked EPSCs evoked by electrical stimulation (ee-EPSCs) of the presynaptic neuron $(n=4)$.

Moreover, both s-EPSCs and ee-EPSCs (Fig. $3 B$ ) were antag- 


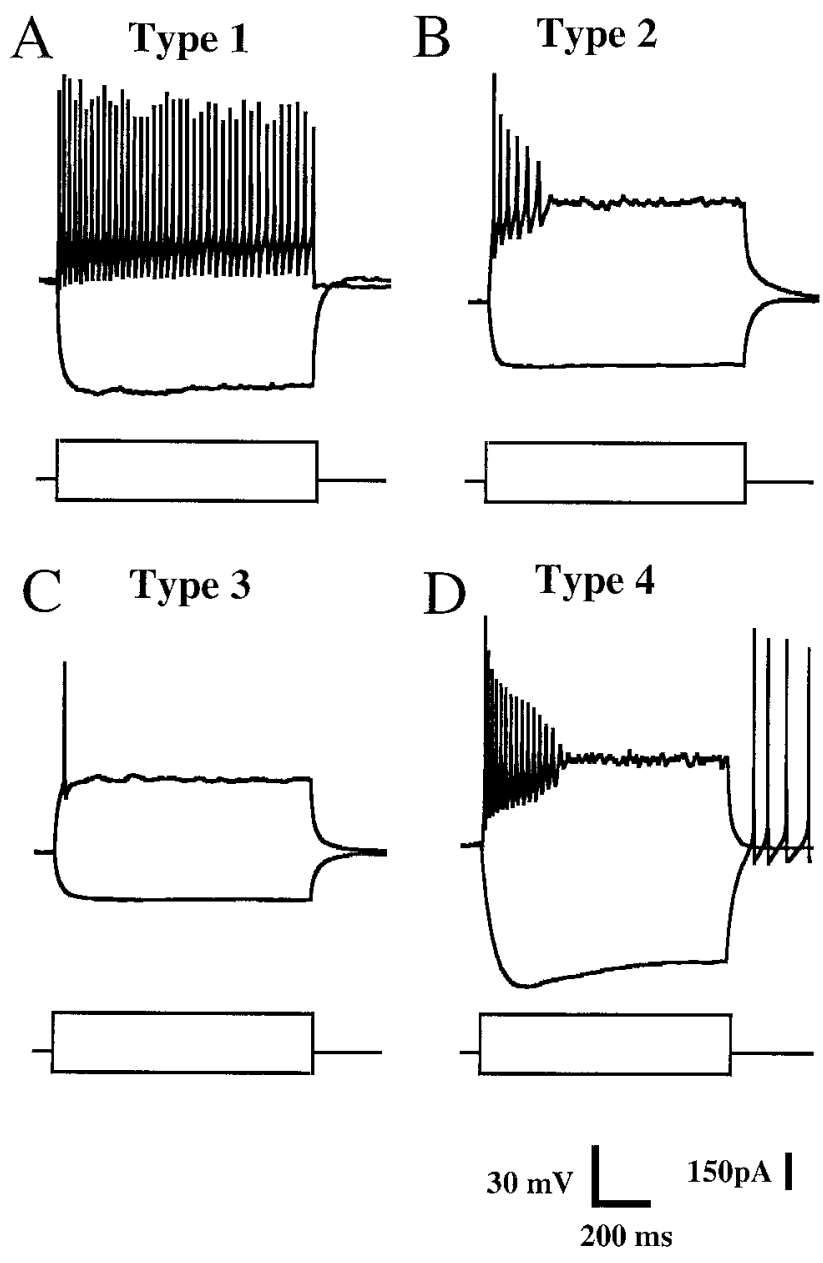

Figure 2. Electrophysiological characteristics of cultured superficial DH neurons. The recordings were obtained with the perforated patch-clamp technique in the current-clamp mode. Each panel shows two typical voltage traces obtained in response to a hyperpolarizing $(-100 \mathrm{pA})$ and a depolarizing $(+180 \mathrm{pA})$ intracellularly applied square current pulse (bottom traces) lasting $900 \mathrm{msec} . A$, Type 1 neurons were characterized by a tonic firing pattern in response to depolarizing current pulses; $\mathrm{V}_{\mathrm{m}}=-61 \mathrm{mV} . B$, Type 2 neurons responded to depolarization with a burst of action potentials; $\mathrm{V}_{\mathrm{m}}=-72 \mathrm{mV}$. $C$, Type 3 neurons fired a single spike at the onset of depolarizing current injection; $\mathrm{V}_{\mathrm{m}}=-72 \mathrm{mV}$. $D$, Type 4 neurons displayed tonic firing for moderate depolarization and spike accommodation for stronger depolarizing currents pulses. These neurons were characterized by the presence of a time-dependent, inwardly rectifying current revealed as an initial sag in the voltage response during the application of hyperpolarizing current pulses. This hyperpolarization was eventually followed by spikes induced by a depolarizing overshoot when the membrane potential returned to the resting potential value; $\mathrm{V}_{\mathrm{m}}=-57 \mathrm{mV}$.

onized by GYKI53655 (10 $\mu \mathrm{M})$, which selectively blocks AMPAtype glutamate receptors $(n=6)$ (Lerma et al., 1997). Both types of EPSCs had fast $(<1 \mathrm{msec})$ rise times and displayed decay phases that could be fitted with a single exponential function (Fig. $3 D)$. The decay time constants of the synaptic currents were $3.0 \pm$ $0.4 \mathrm{msec}(n=7$ cells $)$ for s-EPSCs and $3.1 \pm 0.25 \mathrm{msec}(n=5$ cells) for ee-EPSCs. The exponential fits were performed on current traces that were obtained by averaging 17-76 individual events for s-EPSCs and 50 individual events for ee-EPSCs.

\section{Effect of OT on glutamatergic synaptic transmission}

The effects of OT were tested on $100 \mathrm{DH}$ neurons maintained in culture for 8-21 d. In none of the neurons did we observe an inward or outward current in response to the superfusion of OT (100 $\mathrm{nM})$ for $1 \mathrm{~min}$. In contrast, OT markedly increased the frequency of s-EPSCs in a reversible manner (Fig. $4 A$ ). This type of effect of OT or of an OT receptor agonist (see below) was observed in $35 \%$ (35 of 100) of the neurons tested, suggesting that only a subset of glutamatergic synapses was modulated by OT. The glutamatergic synapses modulated by OT seemed to be preferentially established with type 2 neurons, which received $60 \%$ (21 of 35) of the OT-sensitive synapses. In contrast type 1, 3, and 4 neurons received only 8.5 ( 3 of 35 ), 23 ( 8 of 35 ), and $8.5 \%$ (3 of 35 ) of such synapses, respectively.

The increase in frequency of s-EPSCs varied from cell to cell and ranged from 20 to $830 \%$ (mean, $173 \pm 84 \%$ ). There was no clear relationship between the initial frequency of s-EPSCs under control conditions and the percentage of increase in frequency induced by OT. This increase in frequency generally persisted for 3-5 min after washout of OT. Figure $4 B$ illustrates the amplitude distribution of s-EPSCs before and during application of OT (100 $\mathrm{nM})$. It can be seen that both distributions were similar, and that there was no shift in the main peak of the amplitude distribution during OT with respect to control. The mean amplitude of s-EPSCs was unchanged by OT in two of nine cells tested but was increased by $20.6 \pm 3.5 \%$ in the remaining seven cells. This was in part attributable to the appearance or the increase in the relative contribution of s-EPSCs with amplitudes of $>100 \mathrm{pA}$, which could eventually arise from an action potential activity in the presynaptic element. Therefore, we decided to examine in more detail the effect of OT on miniature EPSCs, i.e., in the presence of TTX $(0.5 \mu \mathrm{M})$, which blocked the generation and the propagation of action potentials.

\section{Effect of OT on miniature EPSCs}

Miniature EPSCs (m-EPSCs) were recorded after blockade of action potentials with TTX $(0.5 \mu \mathrm{M})$. OT $(100 \mathrm{nM})$ reversibly increased the frequency of m-EPSCs $(n=6$, Fig. $5 A)$. The mean percentage of increase in frequency, $156 \pm 73 \%$ (range, 30$480 \% ; n=6$ ), was comparable to that observed for s-EPSCs recorded in the absence of TTX. However, in the presence of TTX we never observed any increase in the mean amplitude of EPSCs, and the amplitude distributions in the absence and presence of OT were very similar (Fig. 5B). Events of large amplitudes $(>100 \mathrm{pA})$ were never recorded even in the presence of OT.

Cumulative probability histograms such as that illustrated in Figure $5 C$ showed in all cases $(n=6)$ a perfect superimposition of the cumulative distributions of m-EPSC amplitudes under control conditions and in the presence of OT (100 nM). The decay kinetics of m-EPSCs were not modified by OT, the decay time constants being $2.82 \pm 0.52 \mathrm{msec}$ in control and $2.85 \pm 0.59 \mathrm{msec}$ in the presence of OT $(n=6)$. Taken together, these observations suggested the absence of a postsynaptic effect of OT on glutamatergic EPSCs.

\section{Pharmacology of the OT effect}

The effect of OT on s-EPSCs $(n=7)$ and m-EPSCs $(n=3)$ was reproduced by the selective OT receptor agonist $\left[\mathrm{Thr}^{4}, \mathrm{Gly}^{7}\right]$-OT (100 nM), as illustrated in Figure $6 A$. [ $\left.\mathrm{Thr}^{4}, \mathrm{Gly}^{7}\right]$-OT increased the frequency of s-EPSCs $(93 \pm 32 \%$; range, $20-210 \% ; n=7)$ and $\mathrm{m}$-EPSCs $(57 \pm 28 \%$; range, $30-115 \% ; n=3)$ in a reversible manner (Fig. 6B) without changing the mean amplitude of s-EPSCs (control, $22.5 \pm 4.6 \mathrm{pA}$; agonist, $24.1 \pm 4.6 \mathrm{pA} ; n=7$ ) and $\mathrm{m}$-EPSCs (control, $15.1 \pm 2.9 \mathrm{pA}$; agonist, $15.6 \pm 3.7 \mathrm{pA} ; n=$ 3 ) or the cumulative probability histogram (Fig. $6 C$ ). 
A
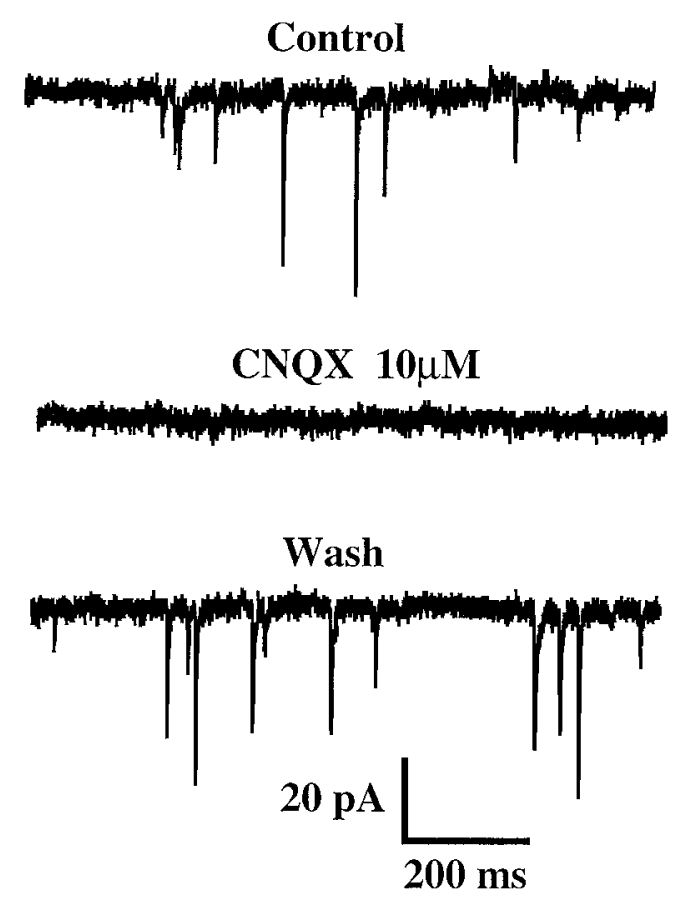

B

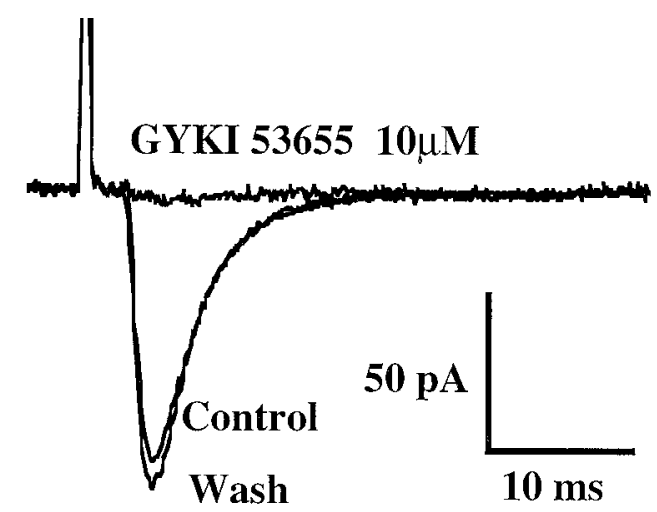

C.1

C. 2

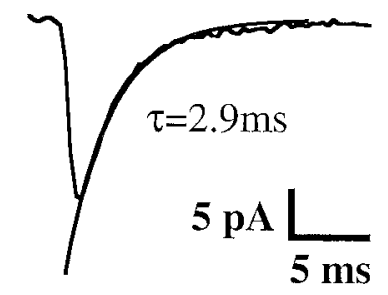

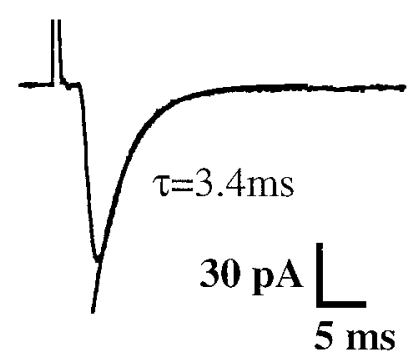

Figure 3. Properties of AMPA receptor-mediated EPSCs in cultured DH neurons. $A$, CNQX (10 $\mu \mathrm{M})$, a competitive antagonist of non-NMDA receptors, reversibly blocked the spontaneous synaptic currents. $B$, The synaptic currents evoked by electrical stimulation were reversibly inhibited by GYKI $53655(10 \mu \mathrm{M})$, a noncompetitive antagonist selective for AMPA receptors. $C$, Decay kinetics of spontaneous $(C .1)$ and electrically evoked $(C .2)$ EPSCs illustrated in $A$ and $B$, respectively. $\tau$ represents the decay time constant of the single exponential fits shown as superimposed solid lines. All traces were recorded at a holding potential of $-60 \mathrm{mV}$.

The effects of OT (100 nM; $n=6)$ and $\left[\mathrm{Thr}^{4}, \mathrm{Gly}^{7}\right]-\mathrm{OT}(100 \mathrm{~nm}$; $n=5)$ were blocked by the selective OT receptor antagonist $\mathrm{d}\left(\mathrm{CH}_{2}\right)_{5}-\left[\mathrm{Tyr}(\mathrm{Me})^{2}, \mathrm{Thr}^{4}, \mathrm{Tyr}-\mathrm{NH}_{2}{ }^{9}\right]$-ornithine vasotocin (dOVT; $100 \mathrm{~nm})$. The mean percentage of inhibition of the OT effect by dOVT was $89.3 \pm 6.7 \%(n=6)$. The effects of dOVT were similar in the absence or presence of TTX.

\section{Effect of OT on electrically evoked EPSCs}

Among eight pairs of neurons tested, OT (100 nM) increased the amplitude of ee-EPSCs by $26 \pm 8 \%$ in three neurons (three of eight $=37.5 \%$ ). This increase in amplitude was reversible (Fig. 7), and no change in the decay time constant of the synaptic currents was observed (control, $3.1 \pm 0.26 \mathrm{msec}$; OT, $2.9 \pm 0.22 \mathrm{msec} ; n=$ 3). The effect of OT persisted for 2-4 min after washout of OT.

\section{Role of extracellular calcium in the effect of OT} on m-EPSCs

When the extracellular $\mathrm{Ca}^{2+}$ concentration was reduced from 2.5 to $0.3 \mathrm{~mm}$ in the presence of $100 \mu \mathrm{M} \mathrm{Cd}^{2+}$ and TTX $(0.5 \mu \mathrm{M})$, the effect of OT was inhibited by $97.1 \pm 1.4 \%(n=3)$ compared with the control effect recorded in the presence of $2.5 \mathrm{~mm}$ external $\mathrm{Ca}^{2+}$.

\section{DISCUSSION}

The aim of the present study was to characterize in cultures of neonatal DH neurons the presence of functional OT receptors and to investigate the consequences of their activation at the cellular level. Our results show that a subset of DH neurons $(35 \%)$ possesses OT receptors, the activation of which facilitates AMPA-type receptor-mediated glutamatergic synaptic transmission by a presynaptic mechanism.

\section{Localization of OT receptors and modulatory effect on excitatory synaptic transmission}

In transverse spinal cord slices, the highest density of OT binding sites was found in the most superficial laminae (I and II) of the DH (Fig. 1A) (Reiter et al., 1994), which receive an OTcontaining innervation from the hypothalamus (Sofroniew, 1985; Cechetto and Saper, 1988). The fact that we detected OT binding sites in our cultures suggested that at least a fraction of the sites observed in the slice preparations was associated with DH neurons.

These OT binding sites corresponded to functional OT receptors, because the effect of OT was reproduced by the specific OT receptor agonist $\left[\mathrm{Thr}^{4}, \mathrm{Gly}^{7}\right]-\mathrm{OT}$ and reversibly blocked by the specific OT receptor antagonist $\mathrm{d}\left(\mathrm{CH}_{2}\right)_{5}-\left[\mathrm{Tyr}(\mathrm{Me})^{2}, \mathrm{Thr}^{4}, \mathrm{Tyr}-\right.$ $\mathrm{NH}_{2}{ }^{9}$ ]-ornithine vasotocin.

Activation of OT receptors never induced a detectable membrane current in the postsynaptic neuron but triggered in a subset of neurons $(35 \%)$ a marked and $\mathrm{Ca}^{2+}$-dependent increase in the frequency of spontaneous and miniature AMPA receptormediated EPSCs, indicating a presynaptic site of action. This effect of OT persisted in the presence of TTX, suggesting that the OT receptors were localized close to the presynaptic terminal. This is in contrast with the situation reported in the supraotic nucleus slices of the rat, in which OT inhibits GABAergic IPSCs by a purely postsynaptic mechanism (Brussaard et al., 1996). Moreover, the effects persisted for 2-4 min after washout of OT, suggesting the involvement of an intracellular relay (second messenger system and/or consequences of $\mathrm{Ca}^{2+}$ influx). 
A
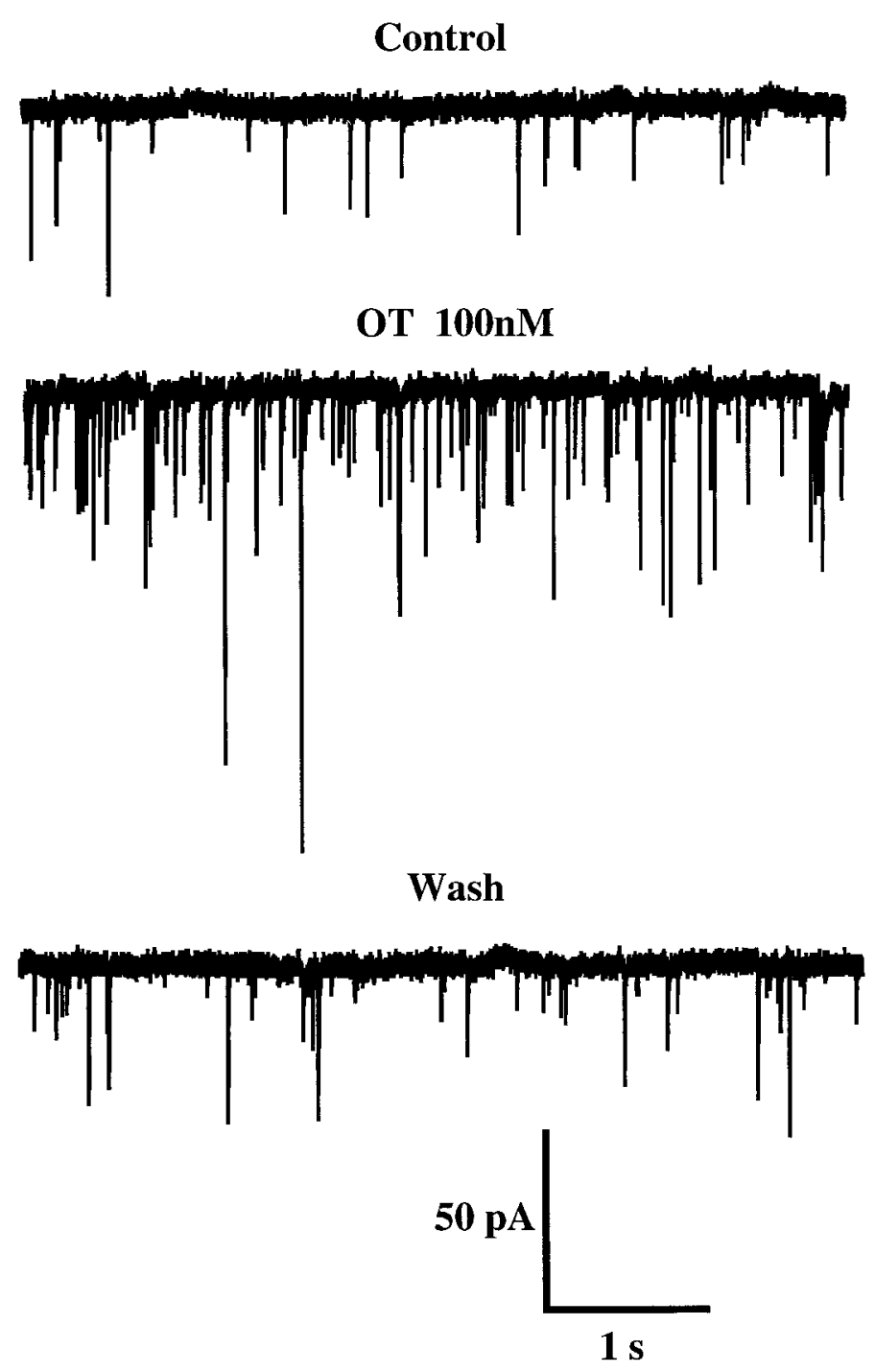

B
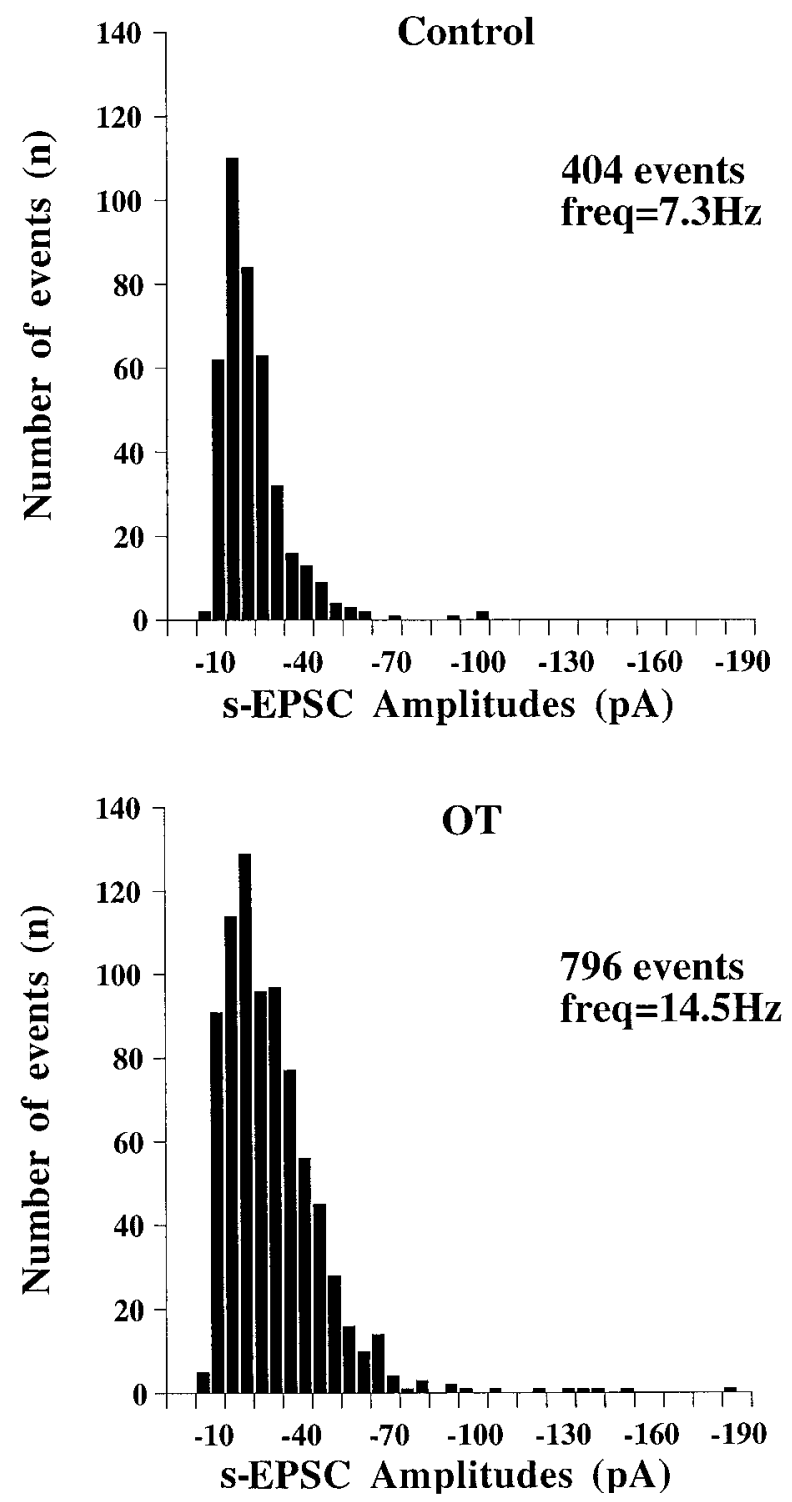

Figure 4. Oxytocin enhances the frequency of s-EPSCs. $A$, Current traces showing s-EPSCs recorded before, during, and after application of OT (100 $\mathrm{nM}$ ). Holding potential $=-60 \mathrm{mV} . B$, Amplitude distribution histograms of s-EPSCs recorded from the neuron $\operatorname{shown}$ in $A$. Oxytocin increased markedly the frequency of spontaneous EPSCs but did not affect the overall amplitude distribution. The number of events corresponds to an analyzed sequence of $55 \mathrm{sec}$ in each situation. The mean frequency ( freq) is obtained by determining the mean number of events per second.

Although our results do not exclude the presence of OT binding sites on primary afferent terminals, it must be emphasized that in the DH, OT-containing fibers do not form axoaxonic synapses with primary afferent terminals but establish axodendritic synaptic contacts with lamina I and II neurons (Rousselot et al., 1990). The latter observation and the absence of axoaxonic contacts of OT-containing terminals with $\mathrm{DH}$ neurons raises a question about the origin of OT activating the receptors on axonal terminals of glutamatergic DH neurons. Although we have no definitive answer to this question, one could speculate that OT could be released either (1) from nearby axodendritic synapses and diff use laterally outside the synapse or (2) into the CSF by hypothalamo-spinal OT-containing fibers. Interestingly, a similar situation has been described for opioid receptors on primary afferent terminals. Indeed, opioid peptides including enkephalin are known to inhibit the release of substance $\mathrm{P}$ at nociceptive primary afferent terminals, although the existence of enkephalincontaining axoaxonic synapses on primary afferents has not been documented (Ma et al., 1997, and references therein).

\section{Possible mechanism of action of OT}

The effect of OT on glutamatergic synaptic transmission was dependent on $\mathrm{Ca}^{2+}$ influx. In rat vagal neurons OT activates a persistent and voltage-dependent TTX-resistant $\mathrm{Na}^{+}$current, which depolarizes the neuron and induces action potential firing (Raggenbass and Dreifuss, 1992). Such a depolarizing effect of OT at the level of presynaptic terminals could possibly induce the opening of voltage-dependent $\mathrm{Ca}^{2+}$ channels, and the resulting $\mathrm{Ca}^{2+}$ influx could facilitate the release of glutamate from a subset of cultured DH neurons. This $\mathrm{Ca}^{2+}$ influx would be blocked by 

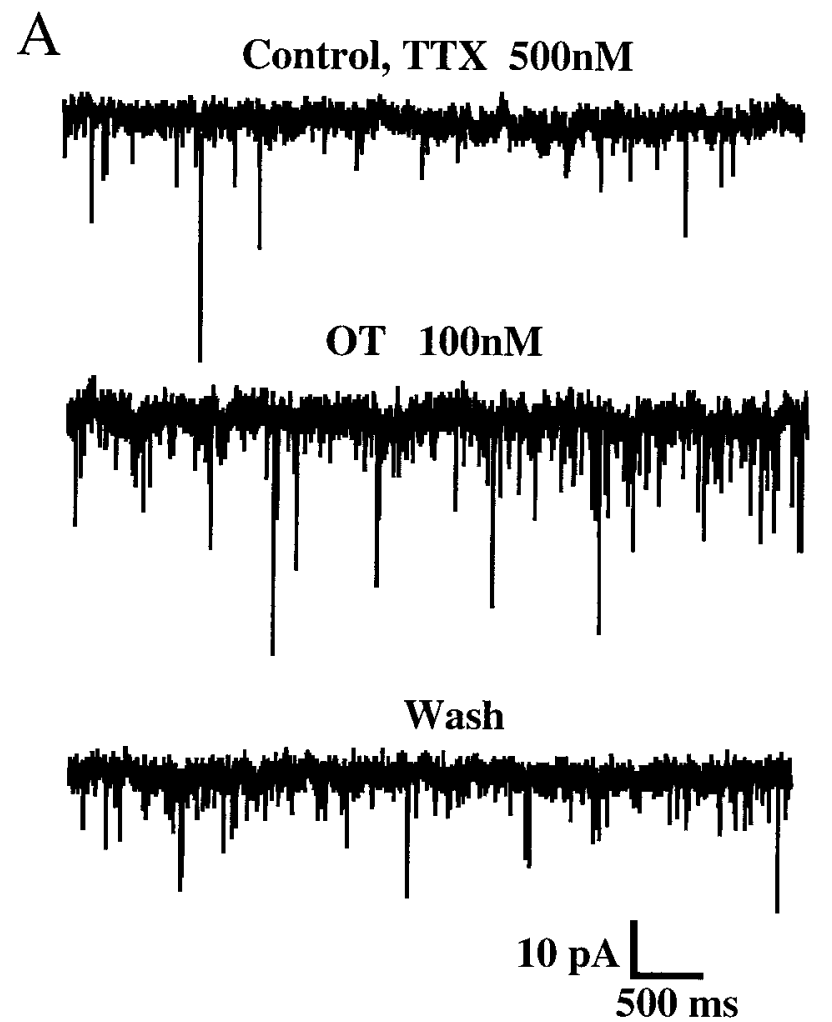

B

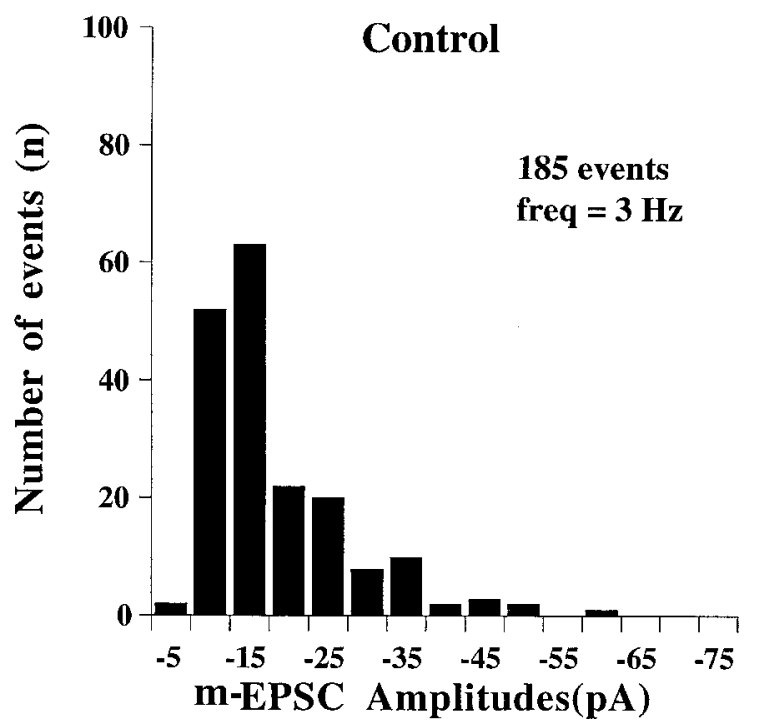

C
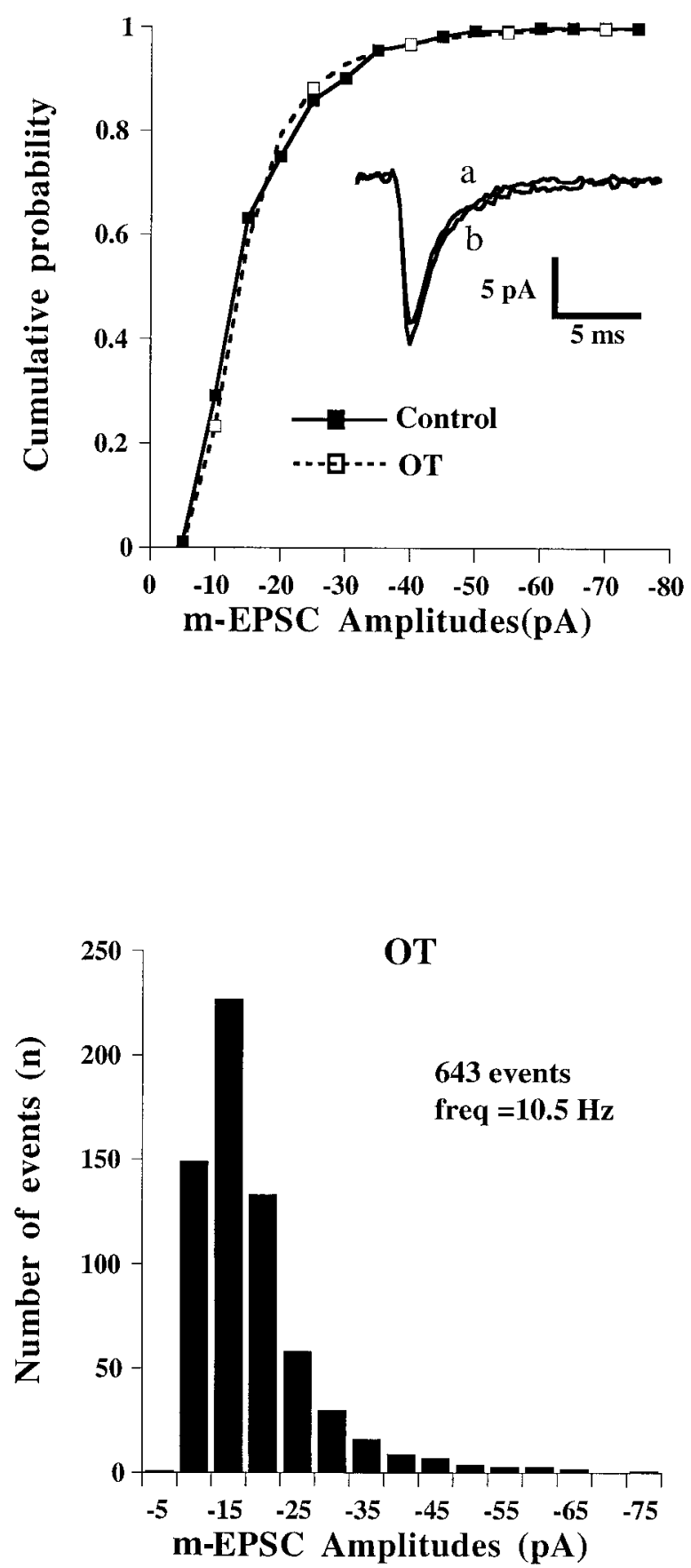

Figure 5. Oxytocin increases the frequency but not the amplitude of miniature EPSCs. $A$, m-EPSCs recorded before, during, and after application of OT $(100 \mathrm{nM})$ in the presence of TTX $(0.5 \mu \mathrm{M})$. Holding potential $=-60 \mathrm{mV}$. $B$, Amplitude histograms of m-EPSCs from the neuron shown in $A$. Note the increase in frequency but the similarity in the amplitude distributions in both situations. The mean amplitudes of m-EPSCs were $-15.6 \pm 0.7 \mathrm{pA}$ (Control) and $-15.9 \pm 0.4 \mathrm{pA}(O T)$. $C$, Cumulative probability histogram of the data illustrated in $B$. No significant difference was seen between the plots before and during application of OT (100 nM), suggesting that the effect of OT was exclusively presynaptic. OT had no effect on the amplitude, and the decay time constant as indicated by superimposed averaged m-EPSCs shown in the inset ( $a$, control; $b$, during OT).

$100 \mu \mathrm{M} \mathrm{Cd}{ }^{2+}$, as observed in our experiments. It is technically impossible to directly measure an OT-induced depolarization of a presynaptic terminal in our cultures. Despite the presence of OT binding sites on the neurites and the cell body of cultured $\mathrm{DH}$ neurons as determined by radioautography, we never detected any depolarizing effect of OT at the level of the cell body of the neurons from which we recorded $(n=100)$. In the absence of TTX, we sometimes observed the induction of s-EPSCs with 
A

$\mathrm{C}$
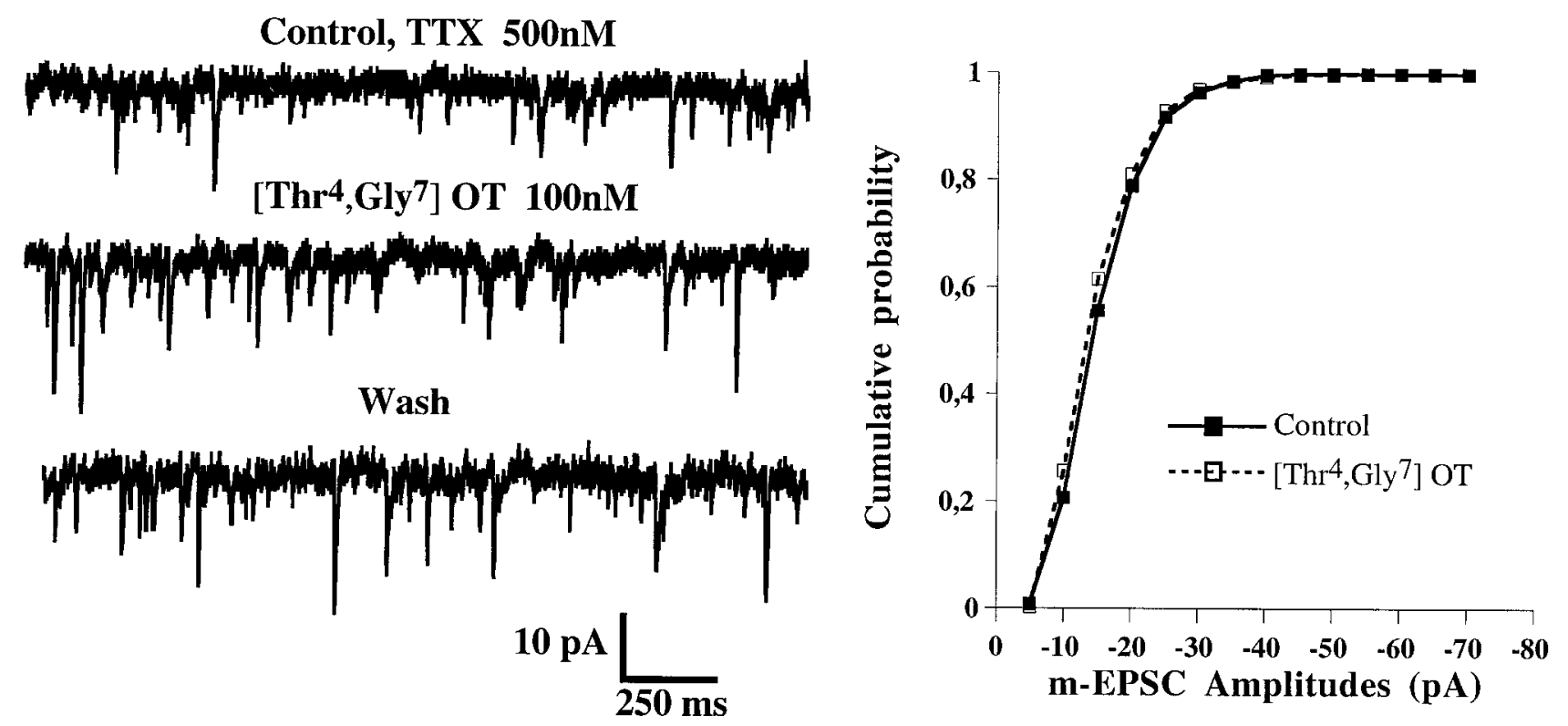

B
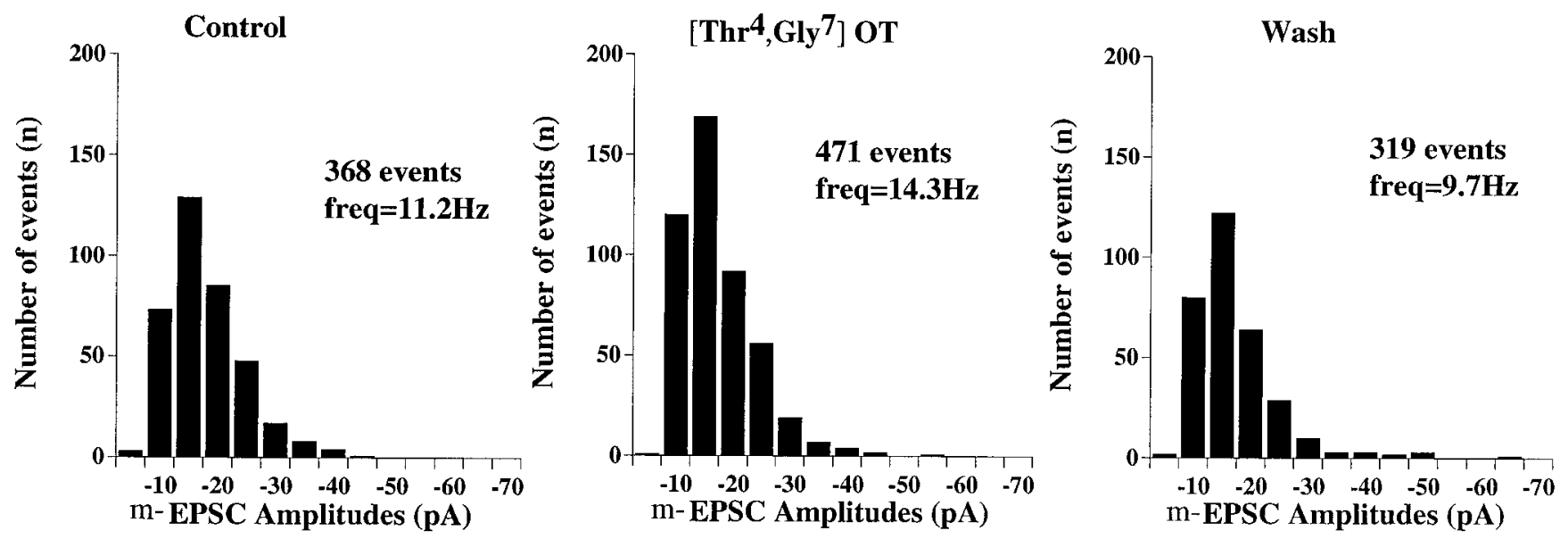

Figure 6. $\left[\mathrm{Thr}^{4}, \mathrm{Gly}^{7}\right]$-OT, a selective OT receptor agonist, increases the frequency but not the amplitude of m-EPSCs. $A$, Current traces showing mEPSCs recorded before, during, and after application of $\left[\mathrm{Thr}^{4}\right.$, Gly $\left.{ }^{7}\right]-\mathrm{OT}(100 \mathrm{nM})$. $B$, Amplitude histograms of m-EPSCs from the neuron shown in $A$. Note the similarity of distribution and the reversibility of the effect of $\left[\mathrm{Thr}^{4}\right.$, Gly $\left.^{7}\right]$-OT. $C$, Cumulative probability histogram of the data in $B$. The cumulative probability ditribution was unchanged before and during application of [ $\mathrm{Thr}^{4}$, Gly $\left.{ }^{7}\right]$-OT (100 nM), indicating the absence of a postsynaptic effect.

amplitudes of $>100$ pA (Fig. 4), which could eventually result from the induction of action potentials in the presynaptic neuron. One explanation could be that this phenomenon was attributable to a polysynaptic effect of OT, i.e., OT inducing the release of glutamate, which in turn could induce the firing of action potentials in a second glutamatergic neuron projecting onto the cell from which we were recording. This is, however, rather unlikely, because we never observed signs of action potential induction at the level of the cell body in the cells from which we recorded $(n=$ 100). A second, more likely, possibility could be that, in the absence of TTX, the depolarizing effect OT at the terminal and/or preterminal level was sufficient to induce locally an action potential-like depolarization through the activation of voltagedependent ion channels.

Alternatively, OT could induce a rise in the intracellular free calcium concentration $\left(\left[\mathrm{Ca}^{2+}\right]_{\mathrm{i}}\right)$ as described in acutely dissociated rat supraoptic nucleus neurons (Lambert et al., 1994) or cultured rat hypothalamic astrocytes (DiScala-Guenot et al., 1994). However, these increases in $\left[\mathrm{Ca}^{2+}\right]_{\mathrm{i}}$ were independent of the external concentration of $\mathrm{Ca}^{2+}$. This was not the case in our study. Moreover, we never observed a $\mathrm{Ca}^{2+}$-dependent inhibition of NMDA receptor-induced currents (data not shown) (Kyrozis et al., 1996) or the activation of $\mathrm{Ca}^{2+}$-dependent membrane currents (e.g., $\mathrm{Ca}^{2+}$-dependent $\mathrm{K}^{+}$or $\mathrm{Cl}^{-}$currents) after the 


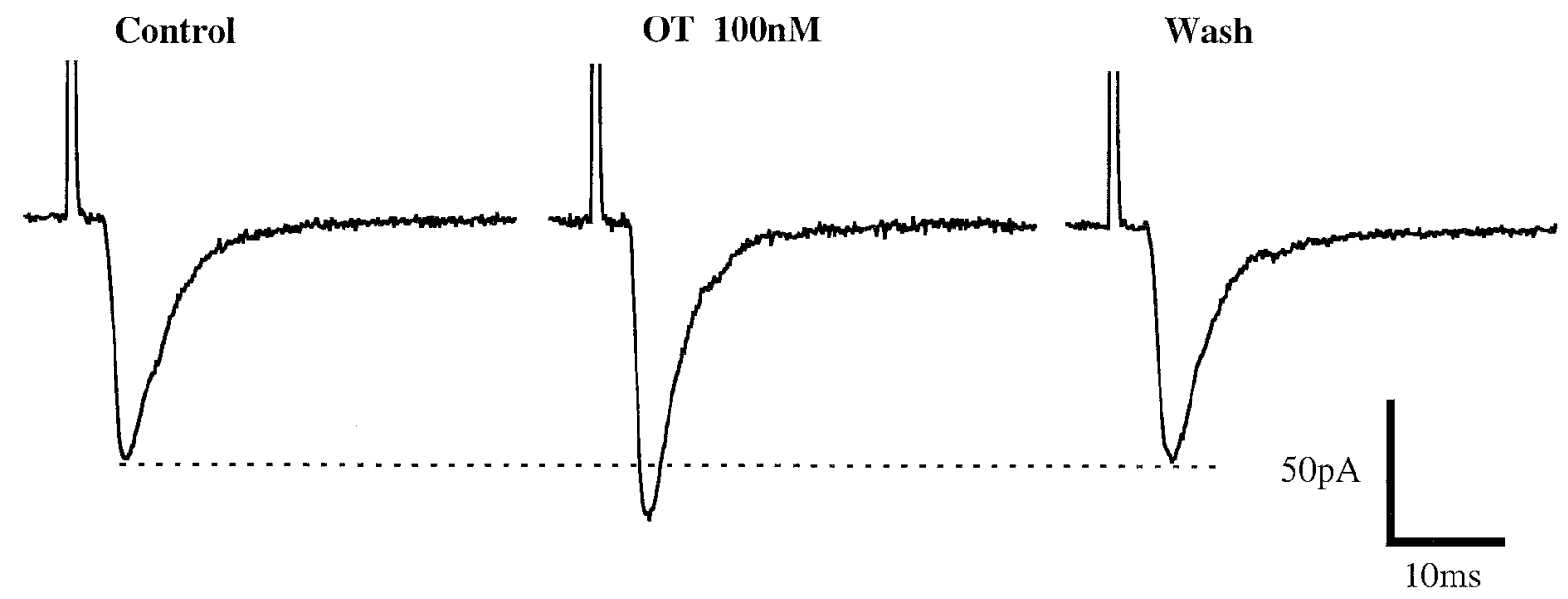

Figure 7. Oxytocin increases the amplitude of electrically evoked EPSCs. Each trace was an average of five consecutive EPSCs evoked by electrical stimulation of a single presynaptic neuron before, during, and after application of OT (100 nM).

application of OT, which would have indicated an elevation in $\left[\mathrm{Ca}^{2+}\right]_{\mathrm{i}}$. A last possibility, which remains to be tested in future work, could be that the OT receptors present on the terminals and on the cell body have different mechanisms of action. In particular, it will be important to verify whether, at the level of the cell body, OT modulates voltage-dependent conductances that are not activated at membrane potentials close to the resting potential $(-60 \mathrm{mV})$.

\section{Physiological significance}

The use of in vitro spinal cord slice preparations has allowed characterization in more detail of the electrophysiological properties of DH neurons with intracellular recording techniques (Murase and Randic, 1983; Thomson et al., 1989; Yoshimura and Jessel, 1989). Recently, Lopez-Garcia and King (1994) have developed a hemisected spinal cord-hindlimb preparation, which allowed them to determine the membrane properties of $\mathrm{DH}$ neurons identified physiologically by stimulation of their cutaneous receptive fields. Interestingly, the properties of the neurons found in our culture are similar to the four types of DH neurons described by these authors, and neurons having the properties of our type 2 neurons were shown to represent $\sim 50 \%$ of the population of nociceptive-specific neurons. Moreover, a recent in vivo study in the cat has indicated that most nociceptive neurons express enkephalin-like immunoreactivity (Ma et al., 1997).

Taking advantage of the labeled grid printed onto the bottom of the culture dishes (see Materials and Methods), we were able to perform immunostainings on neurons previously identified electrophysiologically. We have shown here that $\sim 60 \%$ of type 2 neurons colocalize Met-ENK-LI and GAD-LI, suggesting that these may represent inhibitory DH interneurons possibly activated by nociceptive stimuli. This population of neurons could correspond to that described in laminae II and III by Todd et al. (1992). Moreover, although the results were obtained in different and independent experiments, they suggest that there might be a strong correlation between the fraction of neurons colocalizing Met-ENK-LI and GAD-LI and that of neurons receiving glutamatergic synapses modulated by OT (Fig. 8). Although this is not definitive proof, this correlation allows us to speculate that OTsensitive synapses might be preferentially established with inhibitory interneurons.

If this hypothesis holds true in situ, it would indicate that OT

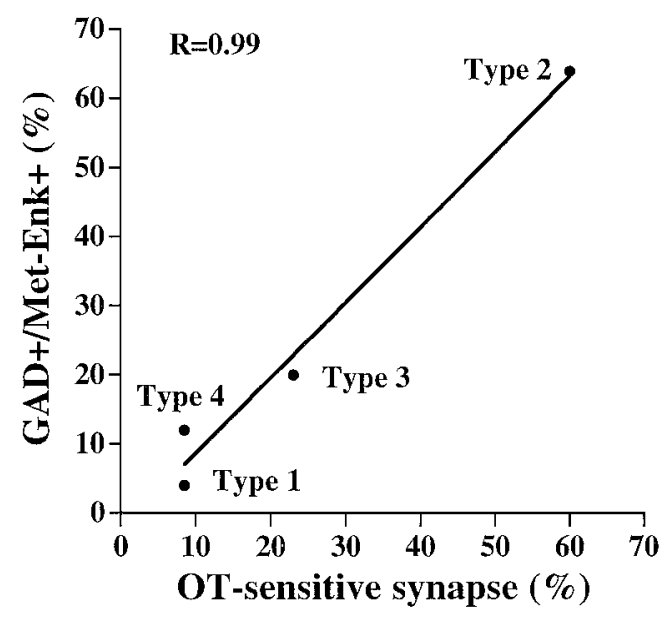

Figure 8. Relationship between the fraction of neurons (in percent) receiving OT-sensitive glutamatergic synapses and the fraction of neurons (in percent) colocalizing GAD-LI and Met-Enk-LI for type 1-4 neurons. The line is a linear regression fit of the data points, indicating a high degree of correlation between the two variables $(r=0.99)$.

facilitates an excitatory synaptic input to nociceptive inhibitory DH interneurons. This phenomenon could in part explain the antinociceptive effects of OT reported in vivo (Arletti et al., 1993; Lundeberg et al., 1994). However, it will be necessary in future work to determine whether OT also directly modulates the release of inhibitory transmitters such as GABA and/or glycine from $\mathrm{DH}$ interneurons. To clarify the role of OT within the DH further, it would be of interest to determine in vivo the consequences of synaptic release of OT, i.e., evoked by electrical or chemical stimulation of the hypothalamic paraventricular nucleus, on the activity of identified nociceptive neurons in the superficial laminae of the DH. A similar experimental approach has recently shown the existence of a pathway originating in the anterior hypothalamus, which specifically inhibits the activity of nociceptive neurons of the deep DH (Workman and Lumb, 1997).

In conclusion, we have developed a culture model of neonatal DH neurons, the properties of which are similar to those recorded in acute spinal cord preparations. Because of optimal application 
of pharmacological substances in dissociated cell culture systems and the possibility of studying the transmission between pairs of identified neurons, we could demonstrate the presence of functional OT receptors on the terminals of a subset of glutamatergic neurons. These receptors could represent the substrate for a descending modulatory action of the OT-containing hypothalamo-spinal projection, which has been described anatomically.

\section{REFERENCES}

Arletti R, Benelli A, Bertolini A (1993) Influence of oxytocin on nociception and morphine antinociception. Neuropeptides 24:125-129.

Bader CR, Bertrand D, Schlichter R (1987) Calcium-activated chloride current in cultured sensory and parasympathetic quail neurones. J Physiol (Lond) 394:125-148.

Besson JM, Chaouch A (1987) Peripheral and spinal mechanisms of nociception. Physiol Rev 67:67-186.

Bottenstein JE, Sato GE (1979) Growth of a rat neuroblastoma cell line in serum-free supplemented medium. Proc Natl Acad Sci USA 76:514-519.

Brussaard AB, Kits KS, de Vlieger TA (1996) Postsynaptic mechanism of depression of GABAergic synapses by oxytocin in the supraoptic nucleus of immature rat. J Physiol (Lond) 497.2:495-507.

Burnstein R, Cliffer KD, Giesler GJ (1987) Direct somato-sensory projections from the spinal cord to hypothalamus and telencephalon. J Neurosci 291:329-344.

Carstens E, Mackinnon JD, Guinan MJ (1982) Inhibition of spinal dorsal horn neuronal responses to noxious skin heating by medial preoptic and septal stimulation in the cat. J Neurophysiol 48:981-991.

Cechetto DF, Saper CB (1988) Neurochemical organization of the hypothalamic projection to the spinal cord in the rat. J Comp Neurol:72:579-604.

Dado RJ, Katter JT, Giesler Jr GJ (1994a) Spinothalamic and spinohypothalamic tract neurons in the cervical enlargement of rats. I. Locations of antidromically identified axons in the thalamus and hypothalamus. J Neurophysiol 71:959-980.

Dado RJ, Katter JT, Giesler Jr GJ (1994b) Spinothalamic and spinohypothalamic tract neurons in the cervical enlargement of rats. II. Responses to innocuous and noxious mechanical and thermal stimuli. J Neurophysiol 71:981-1002.

DiScala-Guenot, Mouginot D, Strosser MT (1994) Increase of intracellular calcium induces by oxytocin in hypothalamic cultured astrocytes. Glia 11:269-276.

Kyrozis A, Albuquerque C, Gu J, MacDermott AB (1996) $\mathrm{Ca}^{2+}$ dependent inactivation of NMDA receptors: fast kinetics and high $\mathrm{Ca}^{2+}$-sensitivity in rat dorsal horn neurons. $\mathrm{J}$ Physiol (Lond) 495.2:449-463.

Lambert RC, Dayanithi G, Moos FC, Richard P (1994) A rise in intracellular $\mathrm{Ca}^{2+}$ concnetration of isolated rat supraoptic cells in response to oxytocin. J Physiol (Lond) 478:275-288.

Lerma J, Morales M, Vicente MA, Herreras, O (1997) Glutamate receptors of the kainate type and synaptic transmission. Trends Neurosci 20:9-12.

Lopez-Garcia JA, King AE (1994) Membrane properties of physiologically classified rat dorsal horn neurons in vitro: correlation with cutaneous sensory afferent input. Eur J Neurosci 6:998-1007.

Lundeberg T, Uvnäs-Moberg K, Ägren G, Bruzelius G (1994) Anti- nociceptive effects of oxytocin in rat and mice. Neurosci Lett 170:153-157.

Ma A, Ribeiro-Da-Silva A, De Koninck Y, Radhakrishnan V, Cuello AC, Henry JL (1997) Substance P and enkephalin immunoreactivities in axonal boutons presynaptic to physiologically identified dorsal horn neurons. An ultrastructural multiple-labeling study in the cat. Neuroscience 77:793-811.

Millan MJ, Schmauss C, Millan MH, Herz A (1984) Vasopressin and oxytocin in the rat spinal cord: analysis of their role in the control of nociception. Brain Res 309:384-388.

Murase K, Randic M (1983) Electrophysiological properties of rat spinal dorsal horn neurones in vitro: calcium-dependent action potentials. J Physiol (Lond) 334:141-153.

Poisbeau P, René F, Egles C, Félix JM, Feltz P, Schlichter R (1996) Characterization of functional GABAergic synapses formed between rat hypothalamic neurons and pituitary intermediate lobe cells in coculture: $\mathrm{Ca}^{2+}$-dependence of spontaneous IPSCs. J Neurosci 16:4835-4845.

Rae J, Cooper K, Gates G, Watsky M (1991) Low access resistance perforated patch recording using amphotericin B. J Neurosci Methods 37:15-26.

Raggenbass M, Dreifuss JJ (1992) Mechanism of action of oxytocin in rat vagal neurones: induction of a sustained sodium-dependent current. J Physiol (Lond) 457:131-142.

Reiter MK, Kremarik P, Freund-Mercier MJ, Stoeckel ME, Desaulles E, Feltz P (1994) Localization of oxytocin binding sites in the thoracic and upper lumbar spinal cord of the adult and post-natal rat: a histoautoradiographic study. Eur J Neurosci 6:98-104.

Rousselot P, Papadopoulos G, Merighi A, Poulain DA, Theodosis DT (1990) Oxytocinergic innervation of the rat spinal cord. An electron microscopic study. Brain Res 529:178-184.

Saper CB, Loewy AD, Swanson LW, Cowan WM (1976) Direct hypothalamo-autonomic connections. Brain Res 117:305-312.

Sofroniew MV (1985) Vasopressin, oxytocin and their related neurophysin. In: Handbook of chemical neuroanatomy. In: GABA and neuropeptides in the CNS, Vol 4, Pt I (Björklund A, Hökfelt T, eds), pp 93-165. Amsterdam: Elsevier Science.

Stoeckel ME, Freund-Mercier MJ (1989) Autoradiographic demonstration of oxytocin-binding sites in the macula densa. Am J Physiol 257:F310-F314.

Thomson AM, West DC, Headley PM (1989) Membrane characteristics and synaptic responsiveness of superficial dorsal horn neurons in a slice preparation of adult rat spinal cord. Eur J Neurosci 1:479-488.

Todd AJ, Spike RC (1993) Localization of classical transmitters and neuropeptides within neurons in laminae I-III of the mammalian spinal dorsal horn. Prog Neurobiol 41:609-645.

Todd AJ, Spike RC, Russell G, Johnston HM (1992) Immunohistochemical evidence that Met-enkephalin and GABA coexist in some neurones in rat dorsal horn. Brain Res 584:149-156.

Willis WD, Westlund KN, Carlton SM (1995) Pain. In: The nervous system of the rat (Paxinos G, ed), pp 725-750. New York: Academic.

Workman BJ, Lumb BM (1997) Inhibitory effects evoked from the anterior hypothalamus are selective for the nociceptive responses of dorsal horn neurons with high- and low-threshold inputs. J Neurophysiol 77:2831-2835.

Xu XJ, Wiesenfeld-Hallin Z (1994) Is systemically administered oxytocin an analgesic in rats? Pain 57:193-196.

Yoshimura M, Jessel T (1989) Membrane properties of rat substantia gelatinosa neurons in vitro. J Neurophysiol 62:109-118. 